\title{
Last Endemic Mammals in Hispaniola
}

\author{
Charles A. Woods
}

\begin{abstract}
After searching many remote regions in the Caribbean island of Hispaniola, the author discovered that the island's last two endemic mammals, formerly believed to be rare, are in fact common in some areas. But human pressures on the hutia Plagiodontia aedium and the solenodon S. paradoxus are such that, unless the Governments of Haiti and the Dominican Republic take effective steps both could soon become extinct.
\end{abstract}

During five research trips between September 1977 and December 1980, I spent 14 months in Haiti and the Dominican Republic investigating both living and extinct land mammals of Hispaniola as part of a project begun in 1973. After searching the island for surviving populations, I found that two endemic mammals still survive, and that there is hope they can be saved from extinction. The fossil record in Hispaniola shows a rich mammalian fauna: 10 rodents, 4-5 insectivores, 4-6 sloths and two primates. Many survived until the time of Columbus, but only these two have survived to the present time. Both, surprisingly, are poorly represented in the fossil record.

The rodent is a medium-sized species of Plagiodontia (Capromyidae), which Oviedo, writing in 1540, described as 'no longer found except very rarely'. ${ }^{7}$ It was not until 1826 that Alexandre Ricord collected two specimens in 'Saint Dominique' which Cuvier in 1836 described as Plagiodontia aedium. ${ }^{4}$ Ricord, like Oviedo, thought it was rare, a view supported by the fact that, despite a number of biological surveys, no more specimens were collected until 1911, when a single animal was taken near Jérémie on Haiti's southern peninsula. Four more were taken in the late 1940s near Miragoane where Reynolds Aluminium Company was developing a bauxite mine, and one of these resulted in Johnson's paper, $A$ Rediscovered Haitian Rodent ${ }^{5}$ Thus, historical accounts consistently implied that the hutia was rarely seen in post-Columbian times. It should be mentioned that in 1923 W.L. Abbott collected 13 specimens in the north-eastern Dominican Republic which were described as a new species, $P$. hylaem. ${ }^{\circ}$

My field work and analysis, however, led me to believe that this hutia was not as rare as previously thought. The hutia is a secretive nocturnal animal that lives in forested areas of rough limestone hillsides and ravines. It can be found in suitable habitat from sea level up to 2000 metres regardless of the amount of rainfall, living in family groups in the same burrow system; commonly three or four animals are found in the same cavity. Usually they feed near the ground and close to the home area, and because they get enough water from their diet of leaves, stems and roots, and occasional small animals, they rarely venture far to drink. In captivity, so long as the diet is leafy vegetation and vegetables, water can be completely withdrawn. The relative medullary thickness of the kidney is four (average of two animals). In captivity they retain their shyness, rarely becoming tame enough to handle easily. They especially like the roots and stems of Colocasia esculenta, Xanthosoma sagittifolium, and Ureka baccifera.

The behaviour of populations from the north-eastern Dominican Republic near Bahia de Samana, however, may differ from the populations in 


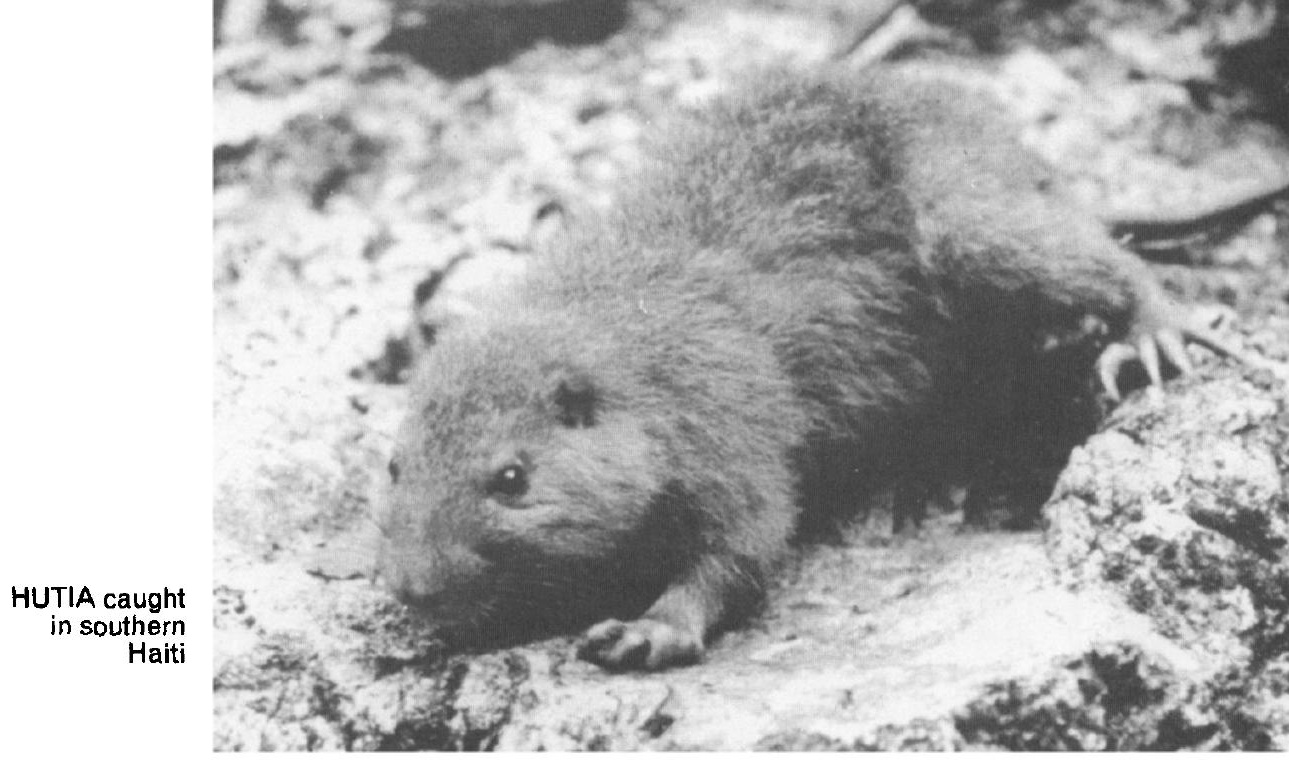

south-western Haiti near Duchity, Jérémie and Miragoane. A professional hutia hunter from near Sabana de la Mar reported that hutias were good climbers and made dens in cavities of large partially decayed trees; they have at least two holes in each tree and travel through the trees rather than come to the ground. The captive animals were collected by climbing trees and taking them from sleeping chambers (Clayton Ray, personal communication, based on conversations in 1958 with the animal collector). This apparent discrepancy may indiacte that different behavioural characteristics are preserved in diverse populations of Plagiodontia.

One knowledgable Haitian mountain farmer near Moron could take us into the steep ravines near his home and show us active hutia homes; all the animals in this area lived in limestone crevices. But he could remember that, as a young man, when tall forest covered the ridges and mountainsides as well as the steep,rocky ravines, he found zagouties (their Haitian Creole name) living in cavities in the trees. I have been told similar stories from the Paillant area in the mountains above Miragoane. The differences in hutia behaviour between

Solenodon Jose Alberto Otterwalder

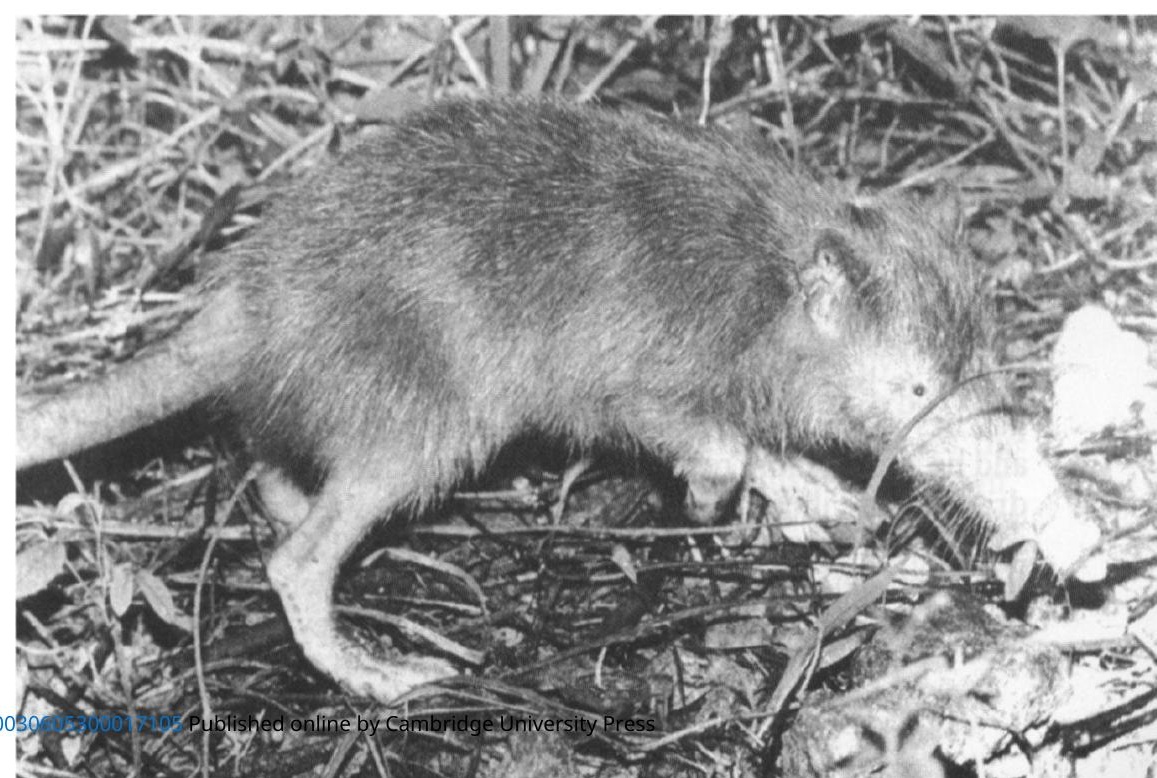




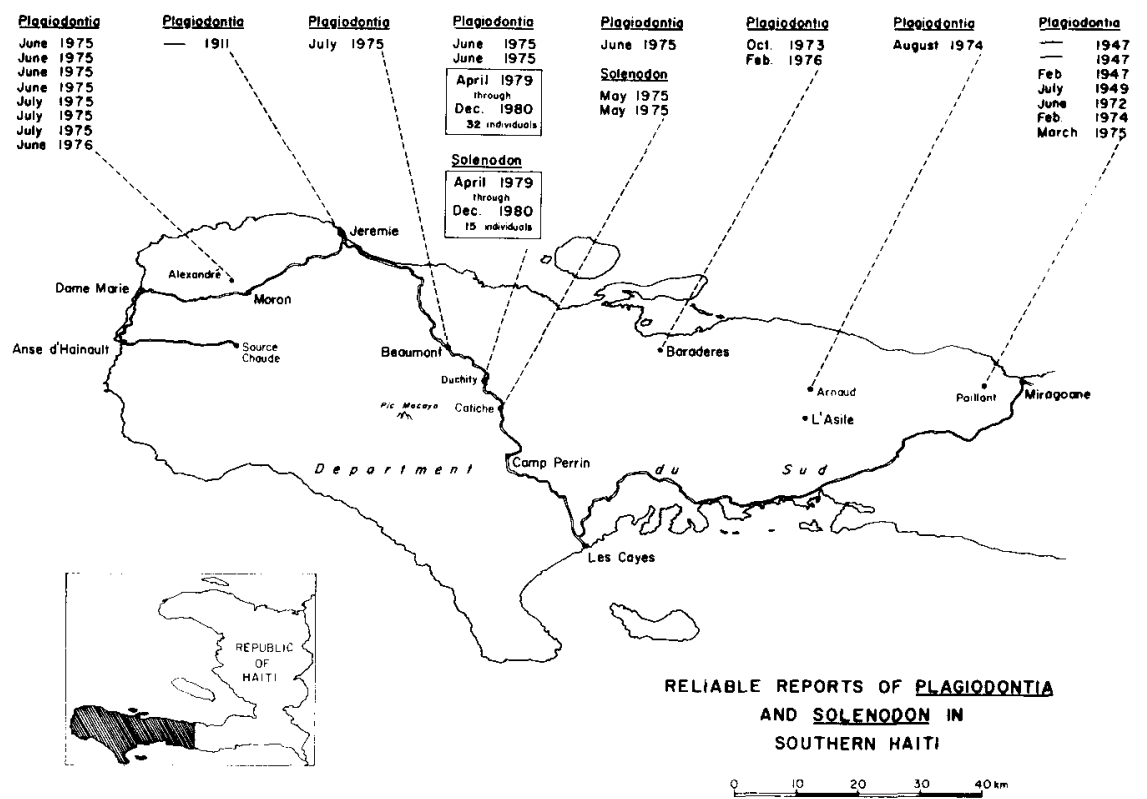

Haiti and the Dominican Republic are associated with differences in available forest cover, and the presence of large old trees; the behaviour may be learned and not genetic. The Hispaniolan hutia is variable in colour and morphology, however, and it is possible that distinct behavioural differences also exist. My analysis of the hutia's habits and life history is based on field work in Haiti, and on observations of five kept in captivity for four years.

Because the animals are difficult to see in their natural habitat, they may seem to be rarer than they really are. Haitian peasant farmers seldom see them. In conversations with hundreds of peasants over the last eight years, I found fewer than fifty who had ever seen or heard of a zagouti, even in the area near Jérémie where I was able to locate eight live animals in a single ravine. I am convinced that the species has been able to survive because of its secretive, nocturnal and localised behaviour. The fossil record indicates that another hutia, Isolobodon portoricensis, almost certainly the one Columbus mentions in his journals, was a hundred times more common than Plagiodontia, even into post-Columbian times. Its remains are so common in midden deposits all over the island that it must have been kept in captivity. I believe it became extinct, as did other endemic rodents of Hispaniola, because of its less secretive habits. In the Dominican Republic many people think Solenodon paradoxus, the strange looking endemic insectivore, is more abundant than Plagiodontia because it is found more frequently by both people and dogs, but my observations indicate that the hutia is the more abundant, and that the reported observations are a reflection of behaviour rather than actual numbers.

This raises a question: Is this hutia now rare in Hispaniola or does it only appear to be so? Suitable habitat in Haiti is now largely restricted to isolated patches in deep, steep ravines, isolated from each other by many kilometres and becoming more restricted each year as land is cleared for gardens. This was dramatically illustrated in April 1979 when I returned to the same ravine in southern Haiti where I had seen five hutias in 1975. Large patches of gardens had been extended into the steep ravine, and whole areas of forest cut and burned on the nearby hillside, even though they are covered with extensive 


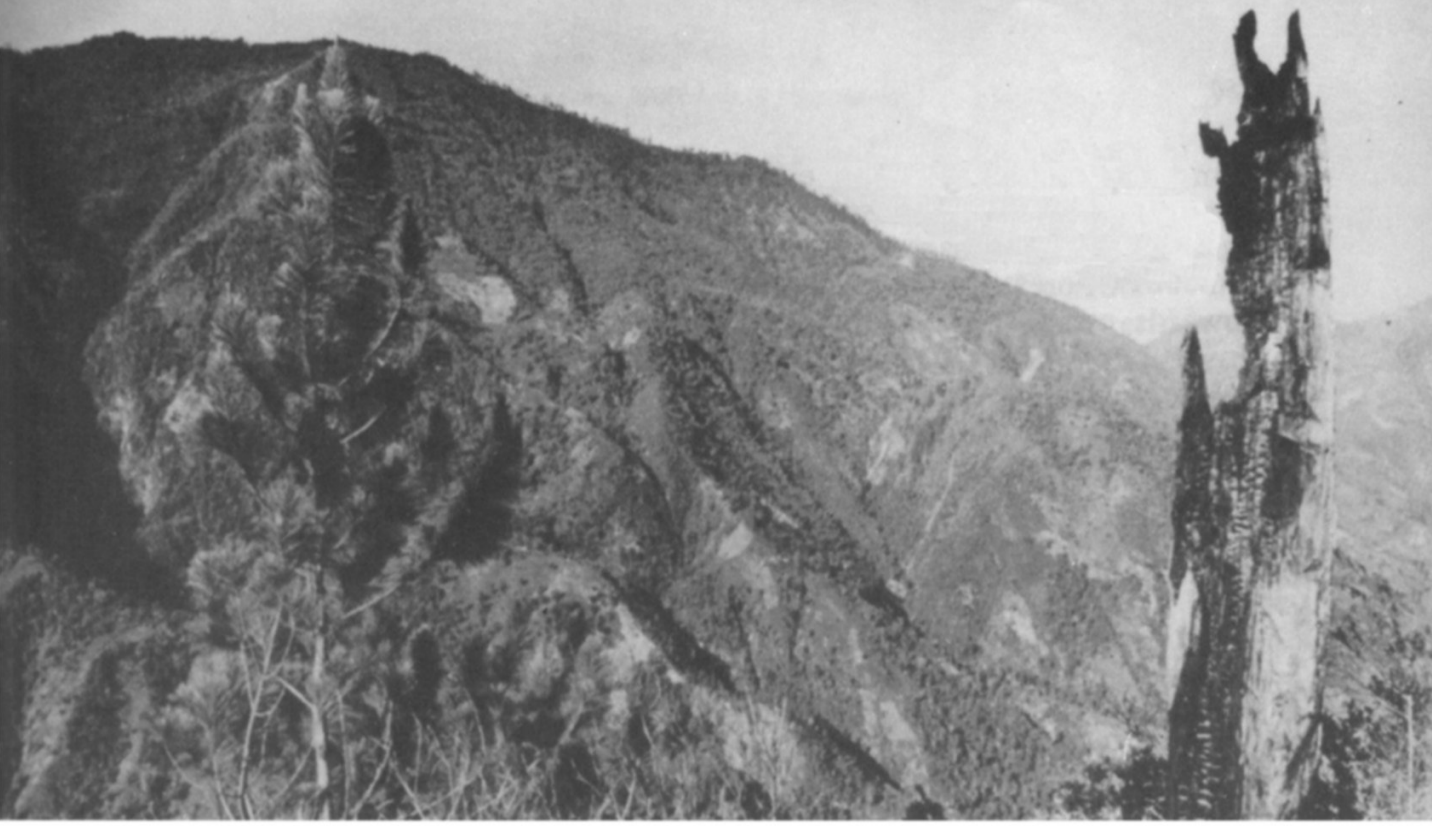

PIC MACAYA, 2347m, the north face, showing how the forest had been burned and cut almost to the summit in 1975 .

limestone deposits and are barely suitable for agriculture. There are few extensive areas of suitable habitat for hutias left anywhere in Haiti, even in the remote Massif de la Hotte area of the far south. The problem is aggravated because hutia's breed only once each year. The gestation period is between 125 and 150 days, and all but one of the known births produced only a single young. The exception was a case of twins from a colony at the US National Zoological Park (Eisenberg, pers. comm.)

The result is that Plagiodontia faces the possibility of extinction in Haiti. Because of the way land was distributed following independence, nearly all the suitable habitat is privately owned, with people and dogs living within a short distance. The hutia will become extinct within this century in Haiti unless the Haitian government takes some dramatic conservation measures to set aside several critical areas of suitable habitat.

The exceptional ability of the species to survive, even under the most unfavourable circumstances, suggests that it is still not too late to save it. In an intensive search of the mountains of southern Haiti, north of Les Cayes, between 3 April 1979 and 3 December 1980, the remains of 32 were found in peasant gardens, along rocky hillsides, and in natural traps formed by deep caves and sinkholes. The species is common in this area of limestone-covered hillsides and severely modified, humid subtropical forest, but most of the suitable areas in this region have recently been planted in gardens or coffee. The human population density is high because the area is bisected by the new mountain road connecting Les Cayes with Jérémie. A few farmers, who work in gardens within a five-mile radius of where the Rivière Glace crosses the mountain highway, told us they see hutias in their gardens just before dawn. More work is underway in this region on the animal's status and biological requirements. There appears to be a significant population in the Morne La Hotte area of Haiti.

The Haitian Government is aware of the status of Plagiodontia and has taken 
some steps that might ensure its preservation in conjunction with a forest conservation and reafforestation programme. The Département de l'Agriculture (DARNDR) has reorganised the Division of Natural Resources to create a Bureau of Forest Resources and Fauna Protection, which is an important step towards establishing a sound conservation programme. In addition, the Institut de Sauvegarde du Patrimoine National (ISPAN) was recently created, by presidential decree, to undertake functions similar to those of the Smithsonian Institution in the United States. Both ISPAN and the Bureau are interested in establishing national parks and natural reserve zones. A national historic park has been established in the area around the Citadelle near Milot, in northern Haiti, and parks are being considered for the Massif de la Selle and Massif de la Hotte areas in the south.

\section{Dominican Republic Situation}

In the Dominican Republic the situation is more encouraging. ${ }^{9}$ People and dogs are mostly in towns, and where the species survives there is still suitable habitat. Moverover, the Government is taking conservation measures. But the growth rate of the Dominican Republic is among the highest in the western hemisphere, and farms and cleared land are spreading across the countryside at an alarming rate. In the areas of the Sierra de Baoruco and Sierra de Neiba, where I worked in 1978, it was possible to see changes each month.

Are there two separate species in the two countries that must be protected, or are all the hutias of Hispaniola of a single species? In an effort to answer this important question I compared populations of Plagiodontia from southern Haiti with those from the north-eastern Dominican Republic. Anderson suggested a single species, based on his analysis of 13 specimens,' but he was able to look at very few confirmed specimens of the southern form, and many workers continue to accept the presence of two species on Hispaniola. I have expanded Anderson's analysis to include over 70 specimens from 10 locations throughout Hispaniola. They are extremely variable in body size and morphology and may fall into a series of local populations, but the analysis indicates that all Hispaniola's surviving populations are of the $P$. aedium. ${ }^{13} 14$

In summary, $P$. aedium still occurs in Haiti and the Dominican Republic. Its preferred habitat is increasingly invaded, but with its amazing ability to survive under difficult conditions, it should be possible in both countries to prevent its total extinction. The best chance is in the Dominican Republic where protection from people and dogs as well as conservation of suitable habitat could ensure its survival. In Haiti the situation is desperate, but not hopeless, because of the animal's tenacity and some encouraging new developments within the Government. I do not recommend large-scale captive breeding. Plagiodontia is difficult to breed in captivity, although the Jersey Wildlife Preservation Trust has had remarkable success breeding the Bahamian hutia, Geocapromys brownii, and new techniques might make it possible to coax Plagiodontia. In this hope an experimental joint captive breeding project has been started by the Florida State Museum and the Parque Zoologico Nacional (ZooDom) of the Dominican Republic. This will utilise the facilities and personnel of the University of Florida during its first four years. If successful, the entire project will be transferred to the National Zoo in Santo Domingo to ensure a Caribbean-based facility for reintroducing Plagiodontia if this is considered necessary and feasible. 


\section{The Solenodon}

The problems for the Solenodon paradoxus are more serious. First described in 1833 by Brandt, it was considered very rare. Verrill stated that: 'For many years it has been commonly considered extinct, and when, in December 1906, I undertook a collecting trip to San Domingo with the avowed intention of obtaining Solenodon, prominent zoologists stated that the quest was hopeless, one of them saying that I would be as likely to secure speciments of ghosts as of $S$. paradoxus'. Verrill did find three specimens; he also found that the species was absolutely unknown over the greater part of the Dominican Republic although some have been caught there since. By 1937 about 30 had been captured, ${ }^{3}$ and since then more than 150 have been taken in the area near San José de las Matas. ${ }^{8}$ In Haiti a few teeth and some claws were collected in 1937 from the foothills of the Morne La Selle range, south of Fond Parisien. ${ }^{10}$ In May 1975, I collected two recently killed specimens at $750 \mathrm{~m}$ in the mountains of the Massif de la Hotte, $27 \mathrm{~km}$ northwest of Les Cayes, ${ }^{12}$ and between April 1979 and December 1980, I found the bones of 15 animals in the same region, $9 \mathrm{~km}$ deeper into the mountains. All the remains were in hillside gardens whose owners thought they were finding hutia bones. The bones were white and weathered, indicating the animals had died several months to a year earlier.

The solenodon is frequently confused with the hutia, even though it is an insectivore with a long, pointed snout. In Haiti it is generally called zagouti (as is the hutia) by the few people who know it, and in the Dominican Republic it is sometimes called a hutia. I have searched for it in all regions of Haiti, but, apart from the 15 dead specimens, I have only three other reliable reports, all from the same remote area surrounding the Massif de la Hotte in the extreme south-west. I conclude that in most of Haiti the animal is 'functionally extinct', persisting only in the remote mountains of the south. ${ }^{2}$ The only chance for saving it lies in the creation of a large natural reserve free of permanent settlements and dogs, for which it is easy prey. Nowhere in Haiti is it possible to get far away from people and dogs, and so the outlook for the solenodon is less encouraging than for the hutia in Haiti.

In the Dominican Republic, many campesinos (farmers) consider the solenodon common. Until recently people tended to live in towns, but as the population increases, and the need for food results in rapid deforestation and the creation of mountain settlements near remote gardens, the less secretive solenodon becomes vulnerable. Even though it appears to be common in certain areas of Haiti (my 1979-80 findings) and the Dominican Republic, this is really an indication of how vulnerable it is to predation, for solenodons are easily killed by dogs. The species could become 'functionally extinct' in the Dominican Republic within this century unless some way is found to protect it. Here, too, the only hope is to set aside large areas of totally protected habitat, which may be difficult in face of increasing agricultural demands. A national park system exists, but there has been little enforcement of protection. The situation in the Dominican Republic has not seemed desperate because there are so many reports of animals, but my experiences in Haiti suggest that this is an artificial situation and that there are not many years left before the solenodon is on the brink of disaster throughout Hispaniola.

To sum up: only one of the two surviving endemic land mammals of Hispaniola seems well suited by habits and habitat preference to survive in the presence of increasing levels of human exploitation. In Haiti the situation is 
desperate. ${ }^{2}$ In the Dominican Republic there is hope that a strong conservation programme and the creation of several natural reserves could save both species. The hutia is the more likely to survive, resembling in its tenacity a tough and wiry Haitian peasant, and indeed, there is a saying in Creole for a bent and battered old mountain peasant: 'Ou semble ak zagouti' - you are like a zagouti. In that saying there is hope of a future for both man and beast. It i : worth the time and money to save these remarkable animals.

\section{Acknowledgments}

I would like to thank Joseph Wainwright, Robert Cassagnol and Julio Barthelemy of th: Département de l'Agriculture, Albert Mangones and Paul Paryski of ISPAN, and Selem Auguste, Al Butterfield, Joubert Celange, Gerard Coupet, Ekke Lemke, Michel Mezile and Andy Wagler, all of Haiti, for helping me with important aspects of this study. In the Dominican Republic, I would like to thank José Alberto Ottenwalder, Eugenio deJ. Marcano, Marcos Peña Franjul and Leonardo Salazar, all of whom provided valuable assistance. The field work was supported by generous financial assistance from the American Philosophical Society, the National Geographic Society, the Organization of American States, the National Science Foundation, the University of Vermont, the University of Florida and a grant from the Fauna and Flora Preservation Society. I must acknowledge the help provided by my family and students, all of whom served as field assistants on one or another long and difficult field trip. A special thanks to them all, especially Maggy and Richard who know first-hand the meaning of the Creole proverb 'Beyond mountains are more mountains'.

\section{References}

1. ALLEN, G.M. 1942. Extinct and vanishing mammals of the Western Hemisphere. Amer. Committee Intern. Wildl. Prot., Spec. Publ. 11:620 pp.

2. ANDERSON, S. 1965. Conspecificity of Plagiodontia aedium and Plagiodontia hylaeum (Rodentia). Proc. Biol. Soc. Wash., 78:95-98.

3. ANON. 1977. Endangered Species in Haiti. Oryx 14:101.

4. CUVIER, F. 1836. Caractères du genre Plagiodonte des habitations Plagiodontia aedium. Ann. Sci. Nat., Paris, ser. 2, 6 (Zool):347-353.

5. JOHNSON, D.H. 1948. A rediscovered Haitian rodent, Plagiodontia aedium, with a synopsis of related species. Proc. Biol. Soc. Wash. 61:69-76.

6. MILLER, G.S. 1927. The rodents of the genus Plagiodontia. Proc. U.S. Natl. Mus. 72:1-8.

7. MILLER, G.C. 1929. Mammals eaten by Indians, owls and Spaniards in the coast region of the Dominican Republic. Smithsonian Misc. Coll. 82:1-15.

8. PENA FRANJUL, M. 1977. Habitas nutritivos del Solenodon paradoxus (Brandt) y el programa de reproducción en captividad.Zoodom. 1:11-25.

9. SALAZAR, L. 1977. Notas generales sobre Plagiodontia sp. con comentarios sobre los especimenes obtenidos por el Zoodom. Zoodom 2:16-23.

10. SANDERSON, I. 1939. Caribbean treasure. Viking Press, New York. 292 pp.

11. VERRILL, A.H. 1907. Notes on the habits and external characters of the Solenodon of San Domingo (Solenodon paradoxus). Amer. 7. Sci., ser. 4, 24:55-57.

12. WOODS, C.A. 1976. Solenodon paradoxus in southern Haiti. F. Mamm. 57:591-592.

13. WOODS, C.A. 1980. El Solenodon paradoxus en el Sur de Haiti. Zoodom y $U N P H U$, Santo Domingo.

14. WOODS, C.A., and E.B. HOWLAND 1979. Adaptive radiation of capromyid rodents: Anatomy of the masticatory apparatus. F. Mamm. 60:95-116.

Dr Charles A. Woods, Department of Natural Sciences, Florida State Museum, University of Florida, Gainesville, FL 32611 USA. 